\title{
Long-term compliance with continuous positive airway pressure in patients with obstructive sleep apnea
}

\author{
Norman Wolkove MD FRCP, Marc Baltzan MD FRCP DABSM, Hany Kamel MD, \\ Richard Dabrusin MD FRCP, Mark Palayew MD FRCP
}

N Wolkove, M Baltzan, H Kamel, R Dabrusin, M Palayew. Long-term compliance with continuous positive airway pressure in patients with obstructive sleep apnea. Can Respir J $2008 ; 15(7): 365-369$.

BACKGROUND: Continuous positive airway pressure (CPAP) is an effective treatment for obstructive sleep apnea (OSA). However, compliance is a significant problem and has been incompletely assessed in long-term studies.

OBJECTIVE: To assess the long-term compliance of OSA patients with CPAP therapy.

SUBJECTS: Eighty patients who had had a diagnosis of OSA at least four years previously and received a written prescription for CPAP were evaluated.

METHODS: Subjects were identified by reviewing sleep laboratory records. Participants were contacted by telephone and were asked to quantitate their CPAP use (hours per night, nights per week) and to evaluate whether there had been improvement in symptoms. Those who commenced but subsequently abandoned therapy and those who never initiated treatment were questioned about their reasons for noncompliance.

RESULTS: Patient demographics included mean $( \pm$ SD) age ( $58 \pm 11$ years), male sex (70 of 80 patients [ $88 \%])$ and mean apneahypopnea index $(70 \pm 44$ events/h). At the time of the interview (64.0 \pm 3.7 months after diagnosis), 43 of 80 patients (54\%) were still using CPAP and most reported an improvement in symptoms. Twelve of 80 patients $(15 \%)$ had abandoned CPAP after using it for $10.1 \pm 15.5$ months, and 25 of 80 patients (31\%) had never commenced therapy after initial diagnosis and CPAP titration. Analysis of scores reflecting initial patient sleepiness revealed a significant association of this symptom with subsequent CPAP compliance.

CONCLUSION: Although many patients with OSA derive subjective benefit from, and adhere to treatment with CPAP, a significant proportion of those so diagnosed either do not initiate or eventually abandon therapy. Initial experience with CPAP appears to be important, reinforcing the need for early education and support in these patients.

Key Words: CPAP; CPAP compliance; Obstructive sleep apnea

Continuous positive airway pressure (CPAP) is currently the Utreatment of choice for patients with obstructive sleep apnea (OSA). Although it is a highly effective treatment, compliance with therapy remains a difficult issue. Many previous studies that have addressed this subject have evaluated compliance over relatively brief periods of time (one to six months) (1-5). Long-term studies are far fewer and studies assessing
Fidélité à long terme au traitement par ventilation spontanée en pression positive continue chez des patients atteints d'apnée obstructive du sommeil

HISTORIQUE : La ventilation spontanée en pression positive continue (ou CPAP, pour continuous positive airway pressure) est un traitement efficace de l'apnée obstructive du sommeil (AOS). Toutefois, l'observance thérapeutique pose un problème important et n'a pas été bien évaluée dans le cadre d'études de longue durée.

OBJECTIF : Évaluer la fidélité à long terme des patients atteints d'AOS à leur traitement CPAP.

SUJETS : Les auteurs ont évalué 80 patients ayant reçu un diagnostic d'AOS et une ordonnance pour un traitement CPAP au moins quatre ans auparavant.

MÉTHODES : Les auteurs ont recensé les sujets à partir des dossiers d'un laboratoire du sommeil. L'équipe a joint les participants par téléphone et les a invités à quantifier leur utilisation du traitement CPAP (heures par nuit, nuits par semaine) et à déterminer s'ils avaient observé une amélioration de leurs symptômes. Elle a en outre demandé aux patients qui ont commencé puis abandonné leur traitement et à ceux qui n'ont jamais commencé leur traitement d'expliquer leur décision.

RÉSULTATS : Les caractéristiques démographiques des patients incluaient l'âge moyen ( \pm écart-type [É.-T.]) $(58 \pm 11$ ans), le fait d'être de sexe masculin (70 patients sur 80 [88 \%]) et l'indice moyen d'apnée-hypopnée (70 \pm 44 incidents/h). Au moment de l'entrevue $(64,0 \pm 3,7$ mois après le diagnostic), 43 patients sur 80 (54\%) utilisaient toujours leur CPAP et la plupart faisaient état d'une amélioration de leurs symptômes. Douze patients sur $80(15 \%)$ avaient abandonné le CPAP après l'avoir utilisé pendant $10,1 \pm 15,5$ mois et 25 patients sur 80 (31\%) n'avaient jamais commencé le traitement après le diagnostic initial et le réglage du traitement CPAP. L'analyse des scores révélant un endormissement initial chez les patients a révélé un lien significatif entre ce symptôme et la fidélité subséquente au traitement CPAP.

CONCLUSIONS : Bien que de nombreux patients atteints d'AOS tirent un avantage subjectif du traitement CPAP et y soient fidèles, une proportion non négligeable de sujets porteurs de ce diagnostic ont choisi soit de ne jamais commencer le traitement ou de l'abandonner en cours de route. L'expérience initiale du traitement CPAP semble jouer un rôle important ici, ce qui rappelle la nécessité de faire un enseignement précoce à ces patients et de leur offrir un soutien.

Mount Sinai Hospital Center, Montreal, Quebec

Correspondence and reprints: Dr Norman Wolkove, 5690 Cavendish Boulevard, Montreal, Quebec H4W 1S7. Telephone 514-369-2222, fax 514-369-2225, e-mail norluco@yahoo.com

compliance years after diagnosis are rare $(6,7)$. In these reports, the reasons for noncompliance have often been inadequately documented. Moreover, compliance may have been overestimated in some because only those patients who actually embarked on CPAP therapy were included. Some patients who are prescribed CPAP may not obtain the device and are therefore not included in any subsequent analysis of compliance. 


\section{TABLE 1}

\section{Patient characteristics $(n=80)$}

\begin{tabular}{lc}
\hline Age, years, mean $\pm \mathrm{SD}$ & $58 \pm 11$ \\
Male subjects, $\mathrm{n}(\%)$ & $70(88)$ \\
Apnea-hypopnea index, events/h, mean $\pm \mathrm{SD}$ & $70 \pm 44$ \\
Continuous positive airway pressure, $\mathrm{cm} \mathrm{H}_{2} \mathrm{O}$, mean $\pm \mathrm{SD}$ & $8.5 \pm 2.2$ \\
Follow-up, months, mean $\pm \mathrm{SD}$ & $64.0 \pm 3.7$ \\
\hline
\end{tabular}

In the present study, we sought to determine how many patients with OSA who had been prescribed CPAP were still using it four or more years after initial diagnosis. We also attempted to elucidate the reasons for abandoning therapy in those who stopped CPAP after an initial trial. Finally, unlike previous studies, we attempted to determine what proportion of patients diagnosed with OSA and given a written prescription for CPAP in fact never even started such therapy.

\section{PATIENTS AND METHODS}

\section{Subjects}

The population studied consisted of patients who had had a sleep study (polysomnography [PSG]) for suspected OSA at least four years before the current survey. To be included, participants had to have had an established diagnosis of OSA with an apnea-hypopnea index (AHI) of more than 10 events/h. Full night diagnostic PSG and subsequent laboratory titration studies had been routinely performed. However, if severe OSA was diagnosed in the first $2 \mathrm{~h}$ of recording, a split night study protocol was used (8). In these studies, approximately one-half of the test night was used for diagnosis and the remainder for CPAP titration. Thus, all patients had had a supervised CPAP trial of at least several hours in duration. Subjects had subsequently met with a physician who had informed them of their diagnosis and the potential benefits of treatment with CPAP. They were given a written prescription for CPAP, usually via nasal mask, and a copy of the prescription was retained in the chart. Basic education regarding CPAP use was given and a follow-up appointment arranged in one month and at regular intervals thereafter. Additional training and support was also provided initially and then on an as-needed basis by the CPAP providers.

\section{Data collection}

The PSG records of 250 sequential patients who had been seen at least four years previously at the Mount Sinai Hospital Sleep Clinic (Montreal, Quebec) were retrieved and reviewed. Eighty-nine patients did not have OSA or were never prescribed CPAP. Eighty-one patients could not be contacted or refused to participate. The 80 patients who agreed to be interviewed formed the population for the present study. The patients were contacted by telephone by a single investigator who was not part of the clinical team (Dr Hany Kamel), and asked to answer a questionnaire regarding their CPAP use. First, they were asked whether they were still using their CPAP device. Those adhering to therapy were asked to estimate the number of nights per week, and hours per night CPAP was being used. They were then asked to subjectively evaluate whether there had been improvement in their sleep and overall level of energy, as well as whether they generally felt better, noticed fewer headaches and were satisfied with the CPAP treatment.
TABLE 2

Long-term continuous positive airway pressure (CPAP) compliance $(n=80)$

\begin{tabular}{lccc}
\hline & Still using CPAP & $\begin{array}{c}\text { Stopped using } \\
\text { CPAP }\end{array}$ & $\begin{array}{c}\text { Never filled } \\
\text { prescription }\end{array}$ \\
\hline $\mathrm{n}(\%)$ & $43(54)$ & $12(15)$ & $25(31)$ \\
Age, years & $57 \pm 9.9$ & $61 \pm 12$ & $57 \pm 13$ \\
Male subjects, $\%$ & 86 & 92 & 88 \\
AHI, events $/ \mathrm{h}$ & $75 \pm 43$ & $61 \pm 34$ & $70 \pm 52$ \\
CPAP, cm $\mathrm{H}_{2} \mathrm{O}$ & $8.7 \pm 2.1$ & $8.8 \pm 3.0$ & $8.0 \pm 1.8$ \\
\hline
\end{tabular}

Values are presented as mean $\pm S D$, unless otherwise indicated. All comparisons between groups were not significant $(P>0.1)$. AHI Apnea-hypopnea index

Those not using CPAP at the time of contact were asked to estimate how long they had tried the device and to document reasons for stopping its use. Patients who failed to fill the initial prescription for CPAP and never initiated therapy were asked to list their reasons for not complying with prescribed treatment.

To determine whether pretreatment symptoms influenced subsequent compliance, the sleepiness score recorded by the physician at the initial clinic visit was used. This rating, which was used at the time, attempted to quantitate patients' perceived sleepiness on a numerical scale (0 to 3 ) ranging from 'none' to 'severe' (9).

The present study was approved by the Mount Sinai Hospital Ethics Committee. Consenting participants were assured that all responses would be regarded as confidential and that their questionnaire responses would not be made available to any party outside the research project.

\section{Statistical analysis}

Data are expressed as mean \pm SD. Significant differences among the three groups, including those who never used CPAP, those who used but gave up CPAP, and the persistent users of CPAP, were evaluated using one-way ANOVA (10). Persistent use of CPAP was assessed by comparing groups using a survival analysis and the $\chi^{2}$ statistic (11). A Cox proportional hazards model was used for the analysis of persistent CPAP use with respect to the clinical factors of age, sex, AHI (in quartiles), CPAP level (in $\mathrm{cm} \mathrm{H}_{2} \mathrm{O}$ ), presence of chronic nasal disorders and sleepiness. Sleepiness scores were compared using Fisher's exact test.

\section{RESULTS}

Patient characteristics are presented in Table 1. A majority of the patients were men, and the AHI ranged from 13 events/h to 209 events/h. The group mean AHI was $70 \pm 44$ events/h, reflecting the frequency of severe OSA in our study group. CPAP had been prescribed in all patients at levels ranging from $5 \mathrm{~cm} \mathrm{H}_{2} \mathrm{O}$ to $16 \mathrm{~cm} \mathrm{H}_{2} \mathrm{O}$ (mean, $8.5 \pm 2.2 \mathrm{~cm} \mathrm{H}_{2} \mathrm{O}$ ). The mean follow-up time was greater than five years (64.0 \pm 3.7 months) and ranged from 51 to 74 months.

Table 2 shows the data on these patients grouped according to their CPAP use. Mean age, AHI, CPAP requirement and sex were not statistically different among the three groups. Fortythree patients (54\%) were still using CPAP at the time that they were contacted. Thirty of these patients $(70 \%)$ were still using the same CPAP as had originally been prescribed. The remainder had had adjustments in their CPAP $\left(-6 \mathrm{~cm} \mathrm{H}_{2} \mathrm{O}\right.$ to $\left.+8 \mathrm{~cm} \mathrm{H}_{2} \mathrm{O}\right)$. 
TABLE 3

Characteristics of patients persistently using continuous positive airway pressure (CPAP) $(n=43)$

\begin{tabular}{lc}
\hline Characteristic/symptoms & $\mathbf{n ~ ( \% )}$ \\
\hline Satisfied with CPAP & $36(83)$ \\
Improved sleep & $39(91)$ \\
Feeling better & $38(88)$ \\
More energy & $33(76)$ \\
Fewer headaches & $7(16)$ \\
\hline
\end{tabular}

TABLE 4

Reasons for abandoning continuous positive airway pressure (CPAP) use $(n=12)$

\begin{tabular}{lc}
\hline Reason & Number of patients \\
\hline Switched to dental appliance & 4 \\
Surgery (uvulopalatopharyngoplasty) & 2 \\
Noise and discomfort of apparatus & 2 \\
Dislike CPAP & 2 \\
Attempted weight loss & 1 \\
Claustrophobia with mask & 1 \\
\hline
\end{tabular}

These patients reported using their CPAP regularly, averaging $6.7 \pm 1.0$ nights/week. Nightly self-reported use averaged $6.6 \pm 1.6 \mathrm{~h}$. They were generally satisfied with their CPAP treatment and reported sleeping well, feeling better and having more energy (Table 3). A minority of patients had noticed fewer headaches after starting CPAP compared with previously.

Twelve patients (15\%) had used CPAP for a period of time but ultimately abandoned its use (Table 2). On average, these patients had used CPAP for $10.1 \pm 15.5$ months (range, 0.5 to 48 months). A variety of reasons were given by these patients for terminating CPAP treatment (Table 4). Some wanted to try alternative therapies such as a dental appliance, surgery or weight loss. Others cited the noise of the machine, discomfort with the mask or a sense of 'claustrophobia' with the apparatus. Two individuals stated a general dislike of CPAP without more specific details being given.

Twenty-five patients (31\%) never filled their initial CPAP prescription (Table 2). Their reasons for not beginning treatment after a diagnostic study and CPAP titration are presented in Table 5. The most common reason stated in this group was a general displeasure or discomfort with the CPAP device as experienced during the titration trial. Ten patients did not comply with treatment because they stated that they did not feel ill and did not perceive a need for intervention. Only three patients did not begin CPAP because they could not afford the equipment and did not have appropriate insurance coverage.

Subjective sleepiness as reported by the patient at the time of diagnosis correlated with subsequent CPAP use (Table 6). Continued CPAP use among those with moderate or severe sleepiness was more than twice that among those with mild or no reported sleepiness $(67 \%$ versus $36 \%$; $\mathrm{P}<0.05)$.

\section{DISCUSSION}

The results of the present study suggest a striking dichotomy in CPAP use and compliance. Approximately one-half of our patients were not using CPAP at long-term follow-up. Most of these individuals had never filled their original
TABLE 5

Reasons for not filling continuous positive airway pressure (CPAP) prescription* $(n=25)$

\begin{tabular}{lr}
\hline Reason & $\mathbf{n}(\%)$ \\
\hline Disliked CPAP during titration trial & $11(44)$ \\
No perceived need by patient & $10(40)$ \\
Unable to afford CPAP & $3(12)$ \\
Alternate treatment sought & $3(12)$ \\
\hline
\end{tabular}

*Two patients gave two reasons each

TABLE 6

Daytime sleepiness and continuous positive airway pressure (CPAP) use* $(n=79)$

\begin{tabular}{lcccc}
\hline $\begin{array}{l}\text { Daytime } \\
\text { sleepiness }\end{array}$ & $\begin{array}{c}\text { Continued } \\
\text { CPAP, } \mathbf{n}\end{array}$ & $\begin{array}{c}\text { Stopped } \\
\text { CPAP, n }\end{array}$ & $\begin{array}{c}\text { Never used } \\
\text { CPAP, n }\end{array}$ & $\begin{array}{c}\text { Compliance } \\
\text { rate, n (\%) }\end{array}$ \\
\hline $\begin{array}{l}\text { No sleepiness or } \\
\text { mild sleepiness }\end{array}$ & 12 & 8 & 13 & $12(36)$ \\
$\quad \begin{array}{l}\text { sleepiness score 0 to 1) } \\
\text { Moderate or severe }\end{array}$ & 31 & 4 & 11 & $31(67)^{\dagger}$ \\
sleepiness (sleepiness \\
score 2 to 3)
\end{tabular}

*One patient did not provide a sleepiness score; ${ }^{\dagger} P<0.05$ for continued CPAP use among those with moderate or severe sleepiness compared with those with mild or no reported sleepiness

CPAP prescription. However, the other one-half of our patient sample surveyed appeared to have complied well with treatment, were satisfied with their CPAP device and continued to derive benefit from its use.

Our study differed significantly from many previous ones evaluating CPAP in two important ways. First, while most previous studies were performed after only months of CPAP use, we evaluated long-term compliance a minimum of four years after initial diagnosis and our mean follow-up time was greater than five years. Second, we assessed compliance rates differently by calculating not only how many patients continued CPAP therapy after its initiation, but also by determining the proportion of patients originally prescribed CPAP who were still using the device in follow-up (including those who chose not to initiate treatment).

It has been estimated that approximately $25 \%$ of all patients with OSA discontinue therapy in long-term follow-up (12). If we define compliance in our group as continued use after initiation of CPAP (excluding the 25 patients who never filled the prescription), the resultant rate would be $78 \%$ (43 of 55 patients), a value similar to that noted by others $(1,7,13,14)$. However, if we include those who were prescribed but never used CPAP, our long-term compliance rate is only $54 \%$.

A number of authors have attempted to use demographic data or initial laboratory results in an effort to predict subsequent CPAP compliance. In our study, age, sex and OSA severity, as judged by the AHI or CPAP pressure requirement, did not differ among groups and therefore could not be used to predict subsequent CPAP use. While some studies $(6,13)$ have noted similar results, others $(7,14)$ have found that CPAP compliance does correlate with the initial AHI. The results for age and sex have similarly been inconsistent. Sin et al (15) found that CPAP use correlated with age and female sex. However, Pelletier-Fleury et al (16), after controlling for confounding variables, found no independent effect of age and 
that female OSA patients were less compliant with CPAP therapy than male OSA patients. As was noted in our study, the impact of OSA on the patient, namely sleepiness, has been consistently mentioned as one of the best pretreatment predictors of long-term CPAP use $(17,18)$. Improvement in sleep even during the initial CPAP titration has also been found to be important in predicting the subsequent use of this treatment modality (19).

Those patients in our study who continued using CPAP may be defined as being highly 'satisfied' with treatment, thus explaining their continued compliance. Most patients reported being satisfied with treatment and experienced improved sleep, feeling better and having more energy. Fewer patients noticed improvement in headache frequency, but this may have been because only a minority reported headache as an initial symptom. These results are consistent with those of other studies in that patients who continue to perceive a benefit from CPAP are more likely to comply with treatment $(20,21)$. Our results also support those of Elkhouli et al (22) who found that improvement in clinical parameters, including sleep, are better predictors of long-term compliance and satisfaction with CPAP than objective data obtained by polysomnography during split night studies.

Those patients who tried CPAP but eventually abandoned its use may be defined as being 'dissatisfied' with treatment. Seven patients switched to alternative forms of therapy (dental appliance, surgery and weight loss), suggesting that they perceived a continued need for treatment but experienced inadequate benefit or discomfort with CPAP. McArdle et al (14) reported that $20 \%$ of OSA patients discontinued CPAP after a period of use, primarily because of a lack of perceived benefit. Discomfort with the apparatus or a sense of claustrophobia with the mask were other reasons given by our patients. Additional reasons for CPAP discontinuation mentioned in the literature include anxiety, inconvenience, frequent nocturnal awakening and partner complaints (23). Nasal discomfort is specifically mentioned frequently by patients and is often the reason for abandoning CPAP therapy. In one study (24), 56\% of those treated with CPAP complained of nasal discomfort. It is at least, in part, related to resultant airway dryness. However, while the addition of humidification has been shown to improve compliance with CPAP in some studies (25), this has not been a universal finding (26). Similarly, although it might be expected that auto-CPAP would enhance patient comfort and improve compliance, Richard et al (27) reported that 25\% of patients in their series discontinued CPAP and that there were no significant differences between the fixed pressure and auto-CPAP users.

Patients who are diagnosed as having significant OSA and are prescribed CPAP but fail to initiate therapy are a distinct group. This group represented approximately one-third of our study population. Pieters et al (28) similarly found that $20 \%$ to $30 \%$ of patients do not accept treatment after diagnosis and a CPAP trial. Rauscher et al (17) found an acceptance rate of only 50\% when offering nasal CPAP therapy to unselected patients with an AHI greater than 15 events/h. Our study suggests that acceptance of prescribed treatment is significantly influenced by the first experience with CPAP during the initial titration trial. The most common reason given for failing to begin therapy in our patients was a dislike or discomfort with CPAP as perceived during that initial exposure. Similarly, in the study by Rauscher et al (17), nonacceptance of CPAP after only one night of use was usually due to a difficulty in initiating or maintaining sleep. These findings suggest that it is important that adequate time and effort be spent to ensure patient comfort at the time of introduction of CPAP if one hopes to optimize acceptance of, and adherence to treatment.

Despite being adequately motivated to attend our sleep clinic, undergo PSG and CPAP titration, and meet with a physician, 10 patients in our study refused CPAP because they did not perceive a need for treatment. The small size of this group and our limited data did not allow us to explore their motivation in more detail. They may have been less symptomatic, but studies $(1-3,5,12)$ have shown that a variety of factors may influence a patient's acceptance of CPAP. Not surprisingly, acceptance of CPAP appears to be dependant on the subjective feeling of impairment by hypersomnolence due to OSA. However, more subtle factors may also be influential. For example, CPAP compliance was shown to be better when the patient initiated referral for treatment rather than their partner (29). This may reflect patients' perceptions of their symptoms and thus need for treatment, or perhaps greater motivation in those who are self-referred.

Our study had several limitations. We did not have follow-up data on those patients who refused to be interviewed. However, the number in this group was very small. One might suspect that these individuals are less likely to be satisfied with CPAP (20). If anything, their inclusion would likely increase the rate of noncompliance. A further limitation of our study was that it was subjective and relied on patients' responses to our questionnaires to determine compliance. No attempt was made to objectively verify or quantitate CPAP use. Subjects may have falsely reported compliance with treatment, or have overestimated CPAP use. Previous studies (30) have found that self-reported compliance rates are higher than those obtained by objective monitoring of CPAP use. Thus, it is conceivable that our longterm compliance rate was actually lower, approaching or falling below the $50 \%$ level. While this level of compliance may be low, it is similar to those found with medication use for asthma or hypertension, and with long-term supplemental oxygen in patients with chronic lung disease (31-33).

\section{CONCLUSIONS}

We have identified distinct populations among patients diagnosed with OSA and prescribed CPAP. Slightly more than one-half of these patients remained compliant and highly satisfied with treatment at long-term follow-up. However, approximately one-half of all such individuals had either not accepted or abandoned CPAP use, often citing discomfort with the apparatus as the reason for noncompliance. Initial experiences with CPAP are important in influencing compliance, underscoring the need for attention to patient comfort, education and early behavioural intervention.

ACKNOWLEDGEMENT: The authors thank Judith Koller for her assistance in the preparation of this manuscript.

FUNDING: This work was supported by a research grant from Mount Sinai Hospital Center, Montreal, Quebec.

\section{REFERENCES}

1. Pépin JL, Krieger J, Rodenstein D, et al. Effective compliance during the first 3 months of continuous positive airway pressure. Am J Respir Crit Care Med 1999;160:1124-9.

2. Stepnowsky CJ Jr, Marler MR, Ancoli-Israel S. Determinants of nasal CPAP compliance. Sleep Med 2002;3:239-47. 
3. Wilk MR, Engleman HM, Douglas NJ, Espie CA. Can psychological factors help us to determine adherence to CPAP? A prospective study. Eur Respir J 2004:24:461-5.

4. Lindberg E, Berne C, Elmasry A, et al. CPAP treatment of a population-based sample - what are the benefits and the treatment compliance? Sleep Med 2006;7:553-60.

5. Budhiraja R, Parthasarathy S, Drake CL, et al. Early CPAP use identifies subsequent adherence to CPAP therapy. Sleep 2007;30:320-4.

6. Sucena M, Liistro G, Aubert G, et al. Continuous positive airway pressure treatment for sleep apnoea: Compliance increases with time in continuing users. Eur Respir J 2006;27:761-6.

7. Bizieux-Thamin A, Gagnadoux F, Binquet C, et al. Long term use of nCPAP therapy in sleep apnoea patients. Rev Mal Respir 2005;22:951-7.

8. Yamashiro Y, Kryger MH. CPAP titration for sleep apnea using a split-night protocol. Chest 1995;107:62-6.

9. American Academy of Sleep Medicine. International classification of sleep disorders, revised: Diagnostic and coding manual. Rochester, Minnesota: American Academy of Sleep Medicine, 2000:16-7.

10. Armitage P, Berry G. Statistical Methods in Medical Research, 3rd edn. Oxford: Blackwell Science, 1994:93-153.

11. Cox DR, Oakes D. Analysis of Survival Data. London: Chapman \& Hall, 1984;124.

12. de Zeeuw J, Baberg HT, Duchna HW, et al. [Locus of control belief is a predictor of CPAP-compliance in patients with obstructive sleep apnea syndrome.] Pneumologie 2007;61:283-90.

13. Waldhorn RE, Herrick TW, Nguyen MC, O'Donnell AE, Sodero J, Potolicchio SJ. Long-term compliance with nasal continuous positive airway pressure therapy of obstructive sleep apnea. Chest 1990;97:33-8.

14. McArdle N, Devereux G, Heidarnejad H, Engleman HM, Mackay TW, Douglas NJ. Long-term use of CPAP therapy for sleep apnea/hypopnea syndrome. Am J Respir Crit Care Med 1999;159:1108-14.

15. Sin DD, Mayers I, Man GC, Pawluk L. Long-term compliance rates to continuous positive airway pressure in obstructive sleep apnea: A population-based study. Chest 2002;121:430-5.

16. Pelletier-Fleury N, Rakotonanahary D, Fleury B. The age and other factors in the evaluation of compliance with nasal continuous positive airway pressure for obstructive sleep apnea syndrome. A Cox's proportional hazard analysis. Sleep Med 2001;2:225-32.

17. Rauscher H, Popp W, Wanke T, Zwick H. Acceptance of CPAP therapy for sleep apnea. Chest 1991;100:1019-23.

18. Engleman HM, Asgari-Jirhandeh N, McLeod AL, et al. Selfreported use of CPAP and benefits of CPAP therapy: A patient survey. Chest 1996;109:1470-6.
19. Drake CL, Day R, Hudgel D, et al. Sleep during titration predicts continuous positive airway pressure compliance. Sleep 2003;26:308-11.

20. Hoffstein V, Viner S, Mateika S, et al. Treatment of obstructive sleep apnea with nasal continuous positive airway pressure. Patient compliance, perception of benefits and side effects. Am Rev Respir Dis 1992;145:841-5.

21. Meslier N, Lebrun T, Grillier-Lanoir V, et al. A French survey of 3,225 patients treated with CPAP for obstructive sleep apnoa: Benefits, tolerance, compliance and quality of life. Eur Respir ] 1998;12:185-92.

22. Elkhouli O, Wolkove N, Baltzan M. Predictors of continuous positive airway pressure (CPAP) compliance and satisfaction after split-night protocol. Chest 2005;128:222S.

23. Zozula R, Rosen R. Compliance with continuous positive airway pressure therapy: Assessing and improving treatment outcomes. Curr Opin Pulm Med 2001;7:391-8.

24. Rakotonanahary D, Pelletier-Fleury N, Gagnadonx F, Fleury B. Predictive factors for the need for additional humidification during nasal continuous positive airway pressure therapy. Chest 2001;119:460-5.

25. Massie CA, Hart RW, Peralez K, et al. Effects of humidification on nasal symptoms and compliance in sleep apnea patients using continuous positive airway pressure. Chest 1999;116:403-8.

26. Haniffa M, Lasserson TJ, Smith I. Interventions to improve compliance with continuous positive airway pressure for obstructive sleep apnoea. Cochrane Database Syst Rev 2004;18:CD003531.

27. Richard W, Venker J, Den Herder C, et al. Acceptance and longterm compliance of nCPAP in obstructive sleep apnea. Eur Arch Otorhinolaryngol 2007;264:1081-6.

28. Pieters TH, Collad PH, Aubert M, et al. Acceptance and long-term compliance with nCPAP in patients with obstructive sleep apnea syndrome. Eur Respir J 1996;9:939-44.

29. Hoy CJ, Vennelle M, Kingshott RN, et al. Can intensive support improve continuous positive airway pressure use in patients with the sleep apnea hypopnea syndrome. Am J Respir Crit Care Med 1999;159:1096-100.

30. Rauscher H, Formanek D, Popp W, et al. Self-reported versus measured compliance with nasal CPAP for obstructive sleep apnea. Chest 1993;103:1675-80

31. Mawhinney H, Spector SL, Kinsman RA, et al. Compliance in clinical trials of two non-bronchodilator, antiasthma medications. Ann Allergy 1991;66:294-9.

32. Rudd P. Clinicians and patients with hypertension: Unsettled issues about compliance. Am Heart J 1995;130:572-9.

33. Barjhoux C, Pépin JL, Deschaux-Blanc, et al. Oxygénothérapie au long cours à domicile : Respect de la prescription médicale et observance d'une durée quotidienne d'au moins 15 heures. Rev Mal Respir 1994;11:37-45. 


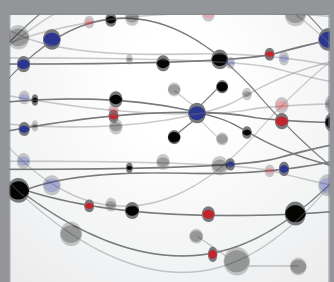

The Scientific World Journal
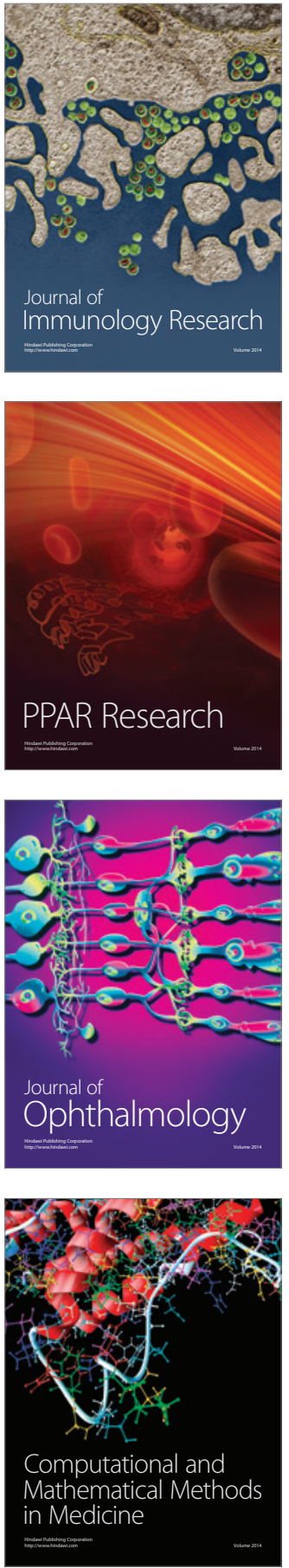

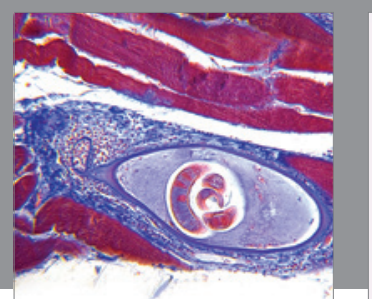

Gastroenterology Research and Practice

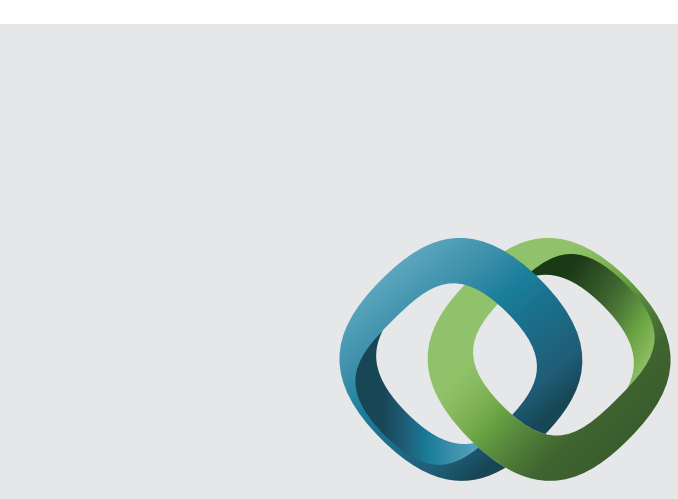

\section{Hindawi}

Submit your manuscripts at

http://www.hindawi.com
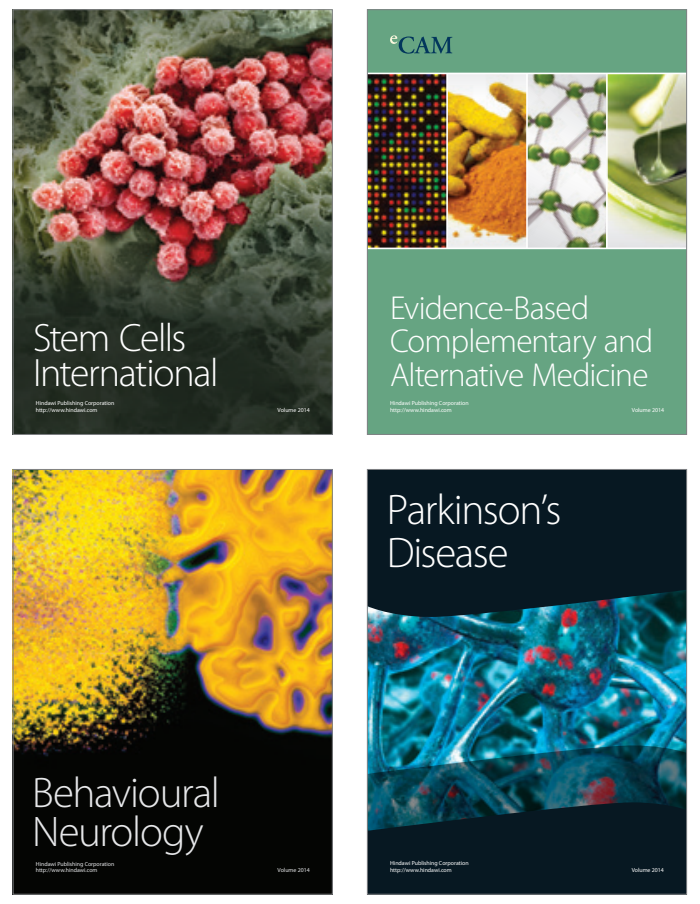
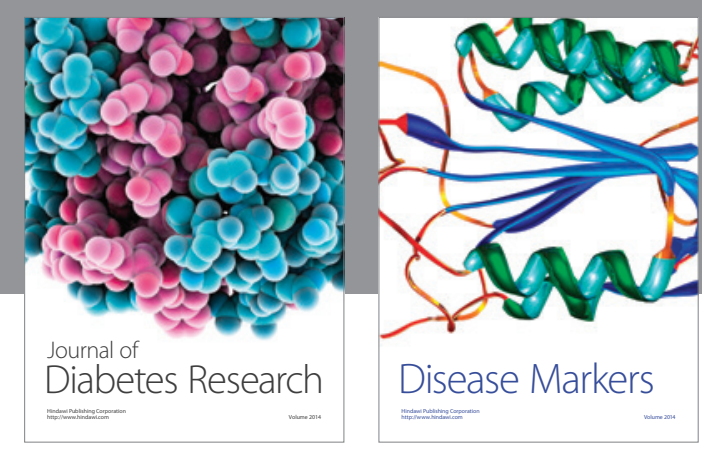

Disease Markers
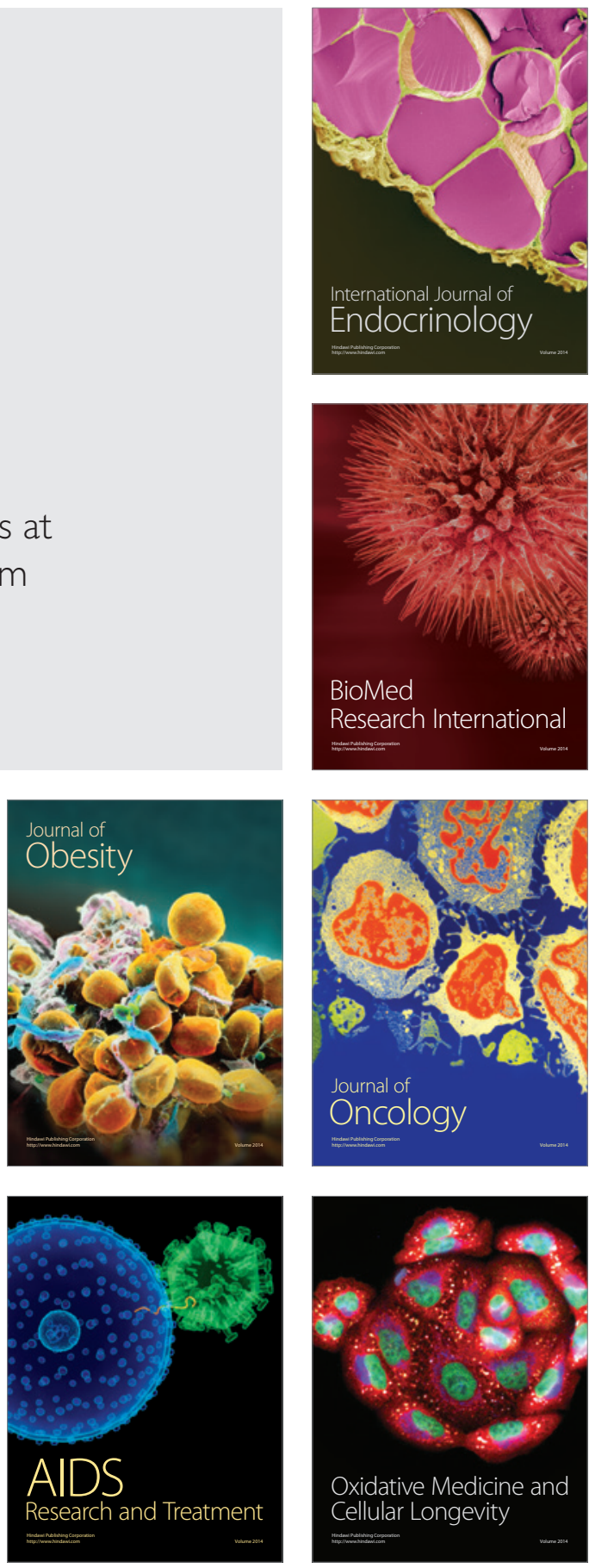